\title{
PATRONATO AGRÍCOLA “VISCONDE DE MAUÁ": da sua origem ao IFSULDEMINAS - Campus Inconfidentes
}

\author{
Antônio Carlos Vilas Boas ${ }^{1}$ \\ José Luis Sanfelice²
}

\section{RESUMO}

\begin{abstract}
A história é uma ciência fundamental para a análise da sociedade. Através dela é possível reconhecer os esforços de muitos homens que lutaram para dialogar com o tempo e realizaram grandes feitos contribuindo com o desenvolvimento da humanidade. No que diz respeito ao aspecto educacional não é diferente. A educação é condição essencial não só para a ampliação do conhecimento, mas, sobretudo, para uma construção social. Assim através de uma análise documental pode-se levantar historicamente, a trajetória do Patronato Agrícola "Visconde de Mauá" até a origem do Instituto Federal de Educação Ciência e Tecnologia do Sul de Minas Gerais (IFSULDEMINAS) - Campus Inconfidentes. Pode ser verificado que o desenvolvimento do município de Inconfidentes, sul de Minas Gerais, está entrelaçado com a história educacional, ofertada ao longo do tempo que permitiu não só formar os jovens para a sociedade, mas, contribuiu significantemente para que o município se destacasse como um polo importante na área educacional.
\end{abstract}

Palavras-chave: História. Evolução. Educação. IFSULDEMINAS.

\section{PATRONATO AGRÍCOLA "VISCONDE DE MAUÁ": from its origin towards IFSULDEMINAS - Campus Inconfidentes}

\begin{abstract}
The history is a fundamental element for the analysis of society. Through it, it is possible to recognize the efforts of many men who have struggled to dialogue with time and have done great things to contribute to the development of humanity. As far as the educational aspect is concerned, it is no different. Education is an essential condition not only for the expansion of knowledge, but above all, for a social construction. Thus, through a documental analysis, the trajectory of the Patronato Agrícola "Visconde de Mauá" until the origin to the Instituto Federal de Educação Ciência e Tecnologia do Sul de Minas Gerais (IFSULDEMINAS) - Campus Inconfidentes could be raised historically. It can be verified that the development of the city of Inconfidentes, south of Minas Gerais, is intertwined with the educational

\footnotetext{
1 Mestre em Educação. Professor do Instituto Federal de Educação Ciência e Tecnologia do Sul de Minas - Campus Inconfidentes. E-mail: carlos.vilas@ifsuldeminas.edu.br

2 Doutorado em Educação. Professor na Universidade do Vale do Sapucaí - UNIVAS, Pouso Alegre/MG. Coordenador do curso de Mestrado em Educação e editor chefe da revista Argumentos Pró-Educação (UNIVAS). E-mail: sanfelice00@gmail.com
} 
history, offered over time that allowed not only trainning the young people for society, but, it also contributed significantly for the municipality so it could stand out as an important pole in the educational field.

Keywords: History. Evolution. Education. IFSULDEMINAS.

\section{PATRONATO AGRÍCOLA "VISCONDE DE MAUÁ": de sU origen al IFSULDEMINAS - Campus Inconfidentes}

\section{RESUMEN}

La historia es uma ciencia fundamental para el análisis de la sociedad. A través de ella es posible reconocer los esfuerzos de muchos hombres que lucharon para dialogar con el tiempo e hicieron grandes hechos contribuyendo con el desarrollo de la humanidad. En lo que respecta al aspecto educativo no es diferente. La educación es condición esencial no sólo para la ampliación del conocimiento, sino sobre todo para una construcción social. Así, a través de un análisis documental se puede levantar históricamente la trayectoria del Patronato Agrícola "Visconde de Mauá" hasta el origen del Instituto Federal de Educación Ciencia y Tecnología del Sur de Minas Gerais (IFSULDEMINAS) - Campus Inconfidentes. Se puede ver que el desarrollo del municipio de Inconfidentes, sur de Minas Gerais, está entrelazado con la historia educativa, ofrecida a lo largo del tiempo que permitió no sólo formar a los jóvenes para la sociedad, sino que también contribuyó significantemente para que el municipio se destacase como un polo importante en el área educativa.

Palabras clave: Historia. Evolución. Educación. IFSULDEMINAS.

\section{INTRODUÇÃO}

Os Patronatos Agrícolas foram estabelecimentos ligados ao amparo à adolescência, educação e trabalho no campo. Essas Instituições Agrícolas se constituíram pelo Decreto $n^{\circ} 12.893$ de 28 de fevereiro de 1918 (BRASIL, 1918) que durou 16 anos. No ano de 1934, esse conjunto de estabelecimentos agrícolas foi depreendido. Os Patronatos eram ligados de imediato aos estabelecimentos agrícolas buscando objetar a uma melhor apreciação técnica em sua constituição para oferecer oportunamente trabalho aos que se afastaram das intuições, segundo escrito em seu decreto de criação (NERY, 2009).

Segundo o mesmo autor, desde sua origem, já demonstravam as suas próprias características dando ênfase no auxílio aos desamparados, embora tenha relatado que estes estabelecimentos possuíam também a obrigação de colaborar com a inovação no setor rural, o que veio com a introdução 
de informações tecnológicas que os conduziram à realização do trabalho, tornando os Patronatos como uma subcategoria que diz respeito ao ensino agrícola.

O Patronato Agrícola "Visconde de Mauá" da cidade de Inconfidentes/MG teve sua importância para o desenvolvimento do município bem como grande contribuição para o desenvolvimento da educação agrícola e tecnológica, passando por vários momentos e desafios, durante décadas do século XX. Mantendo sua tradição e força com a educação agrícola o Patronato acompanhou diversos momentos históricos, cedendo à força da legislação e procurando se adaptar dentro da história.

Analisando historicamente o Patronato Agrícola "Visconde de Mauá", hoje Instituto Federal de Educação Ciência e Tecnologia do Sul de Minas Gerais (IFSULDEMINAS) - Campus Inconfidentes, podemos relatar sua trajetória resumida em: Aprendizado Agrícola de Minas Gerais (1934); Aprendizado Agrícola "Visconde de Mauá (1943); Escola de Iniciação Agrícola "Visconde de Mauá" (1947); Escola Agrícola "Visconde de Mauá" (1950); Ginásio Agrícola "Visconde de Mauá (1964); Escola Agrotécnica Federal de Inconfidentes/MG (1979) e por fim, Instituto Federal de Educação, Ciência e Tecnologia do Sul de Minas Gerais (IFSULDEMINAS) - Campus Inconfidentes (2008).

O estudo desta trajetória nos mostrou o quanto o desenvolvimento do município de Inconfidentes, sul de Minas Gerais, está entrelaçado com a história educacional, ofertada ao longo do tempo que permitiu não só formar os jovens para a sociedade, mas, contribuiu significantemente para que o município se destacasse como um polo importante na área educacional.

\section{PATRONATO AGRÍCOLA}

Em 1918, o Diretor-Geral do Serviço de Povoamento do Ministério da Agricultura Indústria e Comércio, Dr. Dulphe Pinheiro Machado, sensibilizado com o crescimento da promiscuidade em que se encontravam as crianças 
pobres, órfãos e meninos de rua, iniciou a criação e instalação de um modelo de instituição com o objetivo de receber essas crianças desamparadas, transformando-os em jovens agricultores.

Essas instituições receberam o nome de "Patronato Agrícola" que foi promulgado pelo Decreto $n^{\circ}$ 12.893, de 28 de fevereiro de 1918 (BRASIL, 1918), assinado pelo Senhor Presidente da República, Dr. Wenceslau Braz P. Gomes, autorizando o Ministério da Agricultura, Indústria e Comércio à criação dos Patronatos Agrícolas, estabelecimentos de âmbito federal, os Núcleos Coloniais, Postos Zootécnicos e Fazendas-Modelo de criação. Foram criados 23 Patronatos Agrícolas conforme tabela 1.

TABELA 1 - Datas de fundação dos Patronatos Agrícolas no Brasil. UNIVÁS,

Pouso Alegre/MG, 2018

\begin{tabular}{c|c|c|c}
\hline DATA & DECRETO & NOME DOS PATRONATOS & ESTADO \\
\hline 16.05 .1907 & 6.479 & Cria. Dir. do Serv. de Povoamento & Rio de Janeiro \\
28.02 .1918 & 12.893 & M. A. autoriza criar Patronatos & Rio de Janeiro \\
28.02 .1918 & 12.893 & Pat. Agríc. "Pereira Lima" & Minas Gerais \\
28.02 .1918 & 12.893 & Pat. Agríc. "Visconde de Mauá" & Minas Gerais \\
28.02 .1918 & 12.893 & Pat. Agríc. "de Monção" & São Paulo \\
28.02 .1918 & 12.893 & Pat. Agríc. "de Annitópolis" & Santa Catarina \\
15.06 .1918 & 13.070 & Pat. Agríc. "Wenceslau Braz" & Minas Gerais \\
20.07 .1918 & 13.111 & Núcleo Agrícola "Casa dos Ottoni" & Minas Gerais \\
28.07 .1918 & 14.275 & Pat. Agríc. "Barão de Lucena" & Pernambuco \\
29.03 .1920 & 14.118 & Pat. Agríc. "Vidal de Negreiros" & Paraíba \\
25.07 .1920 & 14.275 & Pat. Agríc. "de Jaboatão" & Pernambuco \\
01.10 .1920 & 14.386 & Pat. Agríc. "de Muzambinho" & Minas gerais \\
09.11 .1921 & 15.102 & Pat. Agríc. "de Pelotas" & Rio Grande do Sul \\
01.12 .1921 & 15.149 & Pat. Agríc. "Manoel Barata" & Pará \\
01.12 .1921 & 15.150 & Pat. Agríc. "de Jaboticabal" & São Paulo \\
01.12 .1921 & 15.150 & Pat. Agríc. "José Bonifácio" & São Paulo \\
11.11 .1922 & 15.803 & Pat. Agríc. "Diogo Feijó" & São Paulo \\
21.07 .1923 & 16.105 & Pat. Agríc. "João Coimbra" & Pernambuco \\
21.07 .1923 & 16.105 & Pat. Agríc. "de Rio Formoso" & Pernambuco \\
26.07 .1923 & 16.082 & Pat. Agríc. "do Rio Branco" & Acre \\
16.12 .1925 & 17.139 & Pat. Agríc. "Artur Bernardes" & Minas Gerais \\
16.12 .1925 & 17.140 & Pat. Agríc. "Marquês de Abrantes" & Bahia \\
16.12 .1912 & - & Pat. Agríc. "Floriano Peixoto" & Alagoas \\
\hline
\end{tabular}

Fonte: Silva (1994).

\section{PATRONATO AGRÍCOLA “VISCONDE DE MAUÁ}

A partir do Decreto n 12.893, de 28 de fevereiro de 1918 (BRASIL, 1918), foi criado o Patronato Agrícola no município de Rezende, Distrito de 
Visconde de Mauá, estado do Rio de Janeiro e transferido para o Núcleo Colonial Inconfidentes, no município de Ouro Fino/MG, por ato do Sr. Ministro da Agricultura, Indústria e Comércio, sendo sua instalação, em 05 de abril de 1920.

No decorrer desse mesmo ano, em maio, o Ministro da Agricultura, Dr. Pedro de Toledo, converteu em patronato de menores, a antiga "Fazenda de Sementes" e os campos Elíseos no recém-nascido Núcleo Colonial de Mauá no estado do Rio de Janeiro para introdução de menores de ruas da capital federal.

$\mathrm{Na}$ época o Sr. Eduardo Cotrin Filho, era o prefeito da cidade de Resende, e nomeou o Sr. Agenor Correia para diretor do patronato que já era o responsável pelo núcleo colonial. A instituição recebeu o nome de "Visconde de Mauá". Esta passou a funcionar com o primeiro grupo de meninos vindos das ruas da capital. O primeiro grupo contava com 11 garotos, de 14 a 16 anos de idade, dos quais dois eram originários de estabelecimento corretivo e se evadiram no primeiro dia de internato. Os outros garotos, também em "condição de desajuste", tornavam-se trabalhosos para se realizar o controle. Ocorreram conflitos entre alunos e professores e até mesmo entre professores e o diretor, que levado a uma abertura de sindicância foi dispensado. A partir daí houve ainda a transferência de servidores, sendo o diretor trocado pelo professor Gilberto Guimarães Cravo.

Segundo Guimarães (2010) lamentavelmente o patronato para internação de menores de Resende/RJ, fracassou. Muitos dos internos se evadiram. Em razão dessa situação, o Sr. João de Castro Torres, secretário desse patronato, entregou-o de volta a seus progenitores ou responsáveis mediante documentos. O patronato de Resende/RJ passou a ser intitulado Horto Florestal, e os servidores foram novamente aproveitados ou removidos para outros pensionatos ou colégios equivalentes como no caso do Sr. João de Castro Torres e o Sr. Agenor Correia, que foram removidos para $\circ$ patronato agrícola de Caxambu (1919) e este derradeiro como administrador. 
O diretor de serviços do povoamento, Dr. Dulphe Pinheiro Machado, em companhia do inspetor de igual serviço, Dr. Carlos Pereira da Silva, veio a Inconfidentes com a intenção de analisar na eventualidade da fundação de um patronato no local em outubro de 1919. Tendo descoberto situações oportunas, o Dr. Dulphe tomou rapidamente medidas para sua criação.

Com a independência do núcleo colonial de Inconfidentes/MG desde 1918, ele encontrava-se em posição econômica apreciável. Chegou a informação que nessa sede seria implantado um patronato. Essa notícia não foi vista com bons olhos pela população que ali residia, porque mudaria totalmente a vida social daquela povoação. Ali viviam várias etnias com suas tradições, hábitos e costumes. A comunidade que ali residia ficou em choque com a instalação de uma escola para menores desamparados e de "maus hábitos", que foram criados ao "relento" vindo da casa de repreensão em companhia de uma equipe de pessoas que tinham também hábitos diferentes dos residentes do núcleo colonial de Inconfidentes (GUIMARÃES, 2010). Ocorreu intensa saída de agricultores, negociaram os terrenos e o mesmo aconteceu com os imóveis locais. A vida em seguida foi lentamente esmorecendo o encanto espontâneo dos hábitos e usos das gerações residentes.

O núcleo ainda não tinha dez anos de criação, havia terreno para ser regularizado. Em 1918, aconteceu a designação do Sr. Theóphilo Tavares Paes com a finalidade de exercer as funções de zelar pelo núcleo e de administrador do patronato. Foi-se constituindo então, um novo grupo social de novos hábitos e costumes, criando-se novas amizades. Dois grupos diferiam-se um do outro, mas iam-se aproximando, com pouca intensidade para um ponto comum. Ao decorrer do tempo, as coisas iam se adaptando, servidores da instituição adequaram-se aos hábitos das pessoas, do lugar e as pessoas com os servidores (GUIMARÃES, 2010).

Em 2 de novembro de 1919, o Sr. Theóphilo Tavares Paes, recebera a incumbência de fornecer ao Dr. Carlos Pereira da Silva os dados necessários à confecção do orçamento para as obras necessárias ao pronto funcionamento do Patronato. Também recebeu de Belo Horizonte telegrama 
do delegado do $6^{\circ}$ Distrito do Povoamento do Solo reiterando-lhes ordens para ativar os serviços de adaptação para o Patronato que seria instalado ainda naquele mês. De inicio, foi adaptado o prédio onde funcionava a administração do início do povoamento, em frente ao jardim, na Praça Tiradentes, mais algumas casas.

Muitas dificuldades foram encontradas, pois houve um retardamento do transporte do material, que passou a chegar espaçadamente e com longos intervalos pelas estradas de ferro e principalmente pela deficiência da Estrada de Ferro Rede Mineiras, tendo atrasado o serviço, ultrapassando o tempo determinado.

Em 6 de fevereiro de 1920, o Governo Federal nomeia diretor interino do estabelecimento o Sr. Theóphilo Tavares Paes, que tomou posse do cargo de diretor do patronato no Rio de Janeiro nos primeiros dias de março de 1920 e igualmente nessa época aconteceu a designação dos servidores e docentes que com a equipe concluída, o lar estava pronto para recepcionar os estudantes.

Era essencial material escolar, gêneros alimentícios, produtos de higiene, entre outros. Portanto, na data de 3 de março de 1920, ocorreu a promulgação do $1^{\circ}$ Edital de Concorrência de Gêneros Alimentícios e outros, no jornal a Gazeta de Ouro Fino/MG e colocado em vários estabelecimentos comerciais. Neste contava "kilo assucar refinado de $2^{a}$, doces diversos, banha ou toucinho, bacalhau, batata inglesa, café em pó, carne verde, carne de porco salgada, carne seca, farinha de mandioca, feijão, arroz, kilo macarrão, massa de tomate, pão, queijos, cebola, sal, milho branco ou amarello, graxa para machinismo, litro kerosene, vinagre, alcool".

Em 03 de abril, chegaram 50 alunos do curso complementar de Pinheiros, 03 da Fazenda Santa Mônica, 01 de Delfim Moreira e 02 por ordem do Sr. Juiz de Direito de Ouro Fino/MG. Vieram também alguns professores, funcionários e o arquivo morto. Deu-se início a um novo arquivo e o novo Patronato em Inconfidentes/MG, manteve o mesmo nome: "Visconde de Mauá". 
No início acompanhou o regulamento interno, que foi instituído com o objetivo de zelar pela educação moral ou correção de menores abandonados, que tinha seu jeito apropriado e que o diferenciava dos internatos comuns designados a oferecer conhecimento ou educação intelectual de predileção. Em torno desse ensinamento de renovação foi preparado o plano de estruturação (GUIMARÃES, 2010).

Os alunos que vieram logo de início em maior número, foram criados na ociosidade da vida, arraigados no exercício de maus costumes, inconvenientes enquanto outros apresentavam o espírito deprimente, em uma condição de pobreza psíquica e moral. Fez-se necessário diminuir essa situação em que se encontravam, com jeito, habilidade, zelo e moderação, sem distinção, buscando um novo padrão de conduta moral habitual e constante, a fim de que, ao retornarem à convivência social estivessem aptos, com um discreto preparo e com os costumes contraídos através de responsabilidade e da educação, para as diversidades da vida, de acordo com seus desejos.

Os alunos, após realizarem suas matrículas, eram identificados a partir de então, com uma numeração específica, havendo, dessa forma, um apagamento do sujeito.

O Patronato prosseguia graças ao empenho de seus servidores, que constantemente cumpriam com seus deveres, realizavam de tudo para o crescimento daquela instituição.

Para iniciar os trabalhos agrícolas, a câmara municipal de Ouro Fino/MG fez doação de lotes para o patronato, às margens do Rio Mogi, onde seriam realizadas as tarefas agrícolas dos alunos. O começo desse trabalho foi assustador, mas gerou um entusiasmo em todos. Inicialmente tiveram que abrir caminhos. Esta atividade era feita pelos alunos, que rapidamente passou a ser chamado "caminho do lote do Patronato," pois estimulou o trabalho em favor da prática agrícola. As tarefas, preparatórias essenciais para começar o plantio das culturas, em relação a terra, tornou-se trabalhoso por falta de ferramentas adequadas que possibilitassem a limpeza do terreno. Este era um trabalho braçal feito pelos trabalhadores e 
os alunos. Devido as dificuldades houve atraso na realização dessas atividades, tarefas que foram orientadas pelo Sr. Dr. Luiz da Rocha Vianna, primeiro Agrônomo do Patronato (GUIMARÃES, 2010).

O que tornou tudo muito valioso foi o compartilhamento dos estudantes na operosidade em todas as atividades. Ocorria o concurso dos alunos que no início demonstraram resistência em relação a toda prática de trabalho. Educar não foi fácil, portanto, boa parte dos estudantes eram desobedientes, mas com o tempo e através do castigo que era permitido, também foram inseridos métodos de bons hábitos e educação. Os alunos foram mostrando suas habilidades e interesse pelo trabalho no campo.

Os meninos recebiam uma rigorosa educação, do estilo militar, através do professor de educação física Sr. José Vicente de Souza. Havia também premiações para os alunos e se prosseguia conforme as regras militares. A educação física, praticada pelos estudantes era muito bem aplicada, que além da ginástica sueca e de aparelhos, realizavam também corridas, saltos, evoluções e jogos esportivos. Os alunos tinham sua saúde muito bem cuidada, pois contavam com assistência médica e um enfermeiro que estava sempre pronto para atendê-los em qualquer circunstância (GUIMARÃES, 2010).

As atividades escolares eram distribuídas em quatro turmas primárias, com os cursos preliminares, elementar e médio e havia quatro oficinas: carpintaria, ferraria, alfaiataria e de couros, para o ensino profissional. Quatro mestres de oficinas e um auxiliar agrícola cuidavam desse ensino. Na carpintaria fazia-se desde a serra de tábuas até a fabricação de camas, carabinas de madeira e botinas para os alunos.

O currículo do ensino primário era fundamentado nas disciplinas em vigência em 1918: Canto, Ciências Físicas e Naturais, Caligrafia, Aritmética, Higiene, História do Brasil, Desenho Linear, Geografia, Trabalhos Manuais, Instrução Cívica e Moral e Ginástica. O corpo docente contava com um professor, dois adjuntos e um auxiliar, que também ministravam aulas aos filhos dos colonos do núcleo. O regimento interno de $1^{\circ}$ de janeiro de 1925 
registrava o uso abusivo de castigos corporais e da palmatória, denunciados ao governo federal, o que gerou medidas proibitivas.

Segundo relatório do diretor de 27 de dezembro de 1918, apesar do semestre letivo reduzido, devido à necessidade de atender aos trabalhos tanto agrícolas quanto escolares, em menos de três meses era notável a elevação do nível geral da instrução; houve entrega do prêmio presidente da República aqueles que conseguiram se destacar.

O processo de avaliação era mensal, com banca examinadora, e os resultados enviados à Superintendência no Rio de Janeiro. A procedência dos alunos era dos estados do Rio de Janeiro, São Paulo e Minas Gerais, quadro que se manteve até 1933.

A escassez de mão de obra especializada prejudicou 0 preenchimento de vagas de profissionais, quando da instauração do Patronato. Durante o período em que teve êxito, permaneceram 21 pessoas em cargos, porém a crise econômica que surgiu com a primeira Guerra Mundial, forçou a demissão de funcionários, por falta de verbas.

O material de uso pessoal dos internos, como roupas de cama, mesa e banho e material escolar, era concedido pela União. Existia uma inquietação com o acompanhamento semanal do estado clínico-geral dos alunos, atestado através de uma carteira de saúde individual, com relatório médico. A saúde e a formação militar eram os setores mais cobrados na época.

Através do Decreto Federal no 13.706, de 25 de julho de 1919 (BRASIL, 1919), confere-se aos Patronatos Agrícolas um novo Regulamento.

Foi necessário realizar algumas melhorias prediais, além de fazer a ampliação construindo mais um pavilhão, porque naquela época o Pensionato possuía 150 menores. Assim a câmara municipal de Ouro Fino/MG, não mediu esforços e comprou um terreno de 27 hectares e mais metade de outro lote, com uma extensão de 13 hectares, área considerável para a edificação de mais um bloco e assim acomodar 200 estudantes.

Após fazer saber o órgão abalizado, o Sr. Theóphilo Tavares Paes, logo recepcionou o ofício $n^{\circ} 1.544$, de $1^{\circ}$ de junho de 1921, da Direção de Serviço 
de Povoação, que ordenava a edificação de um prédio com 16 metros defronte, junto do edifício que agora auxilia o Patronato. Onde tudo prosseguia sem perda de tempo, embora tenha tido, algum contratempo para compra do material.

Em 1922, os contratempos que derivavam dos servidores, com o passar do tempo foram mudando. Os estudantes iam se adequando e com a prática do trabalho, demonstravam algum tipo de vocação, de acordo com o aproveitamento, por meio de uma rígida escolha, praticada não só entre os empregados, mas sobretudo, entre os discentes.

No passar deste mesmo ano, todos os trabalhos correram muito bem. Mas, o atraso no pagamento dos servidores, gerou estado de ansiedade e autêntica humilhação. Apareceu outro obstáculo, este com relação à moradia para os funcionários, porém estava previsto ampliar o número de empregados e também o de alunos. Aconteceu outro empecilho, pois não existia nenhuma casa para aluguel na localidade. Era impossível a moradia dos servidores ser em Ouro Fino, porque em sua maior parte, devido à função, não conseguiriam distanciar-se da instituição. Existia, pois urgência na construção de algumas moradias ou comprar as propriedades privadas que já existiam, com o objetivo de ajustar a posição dos servidores.

Consecutivamente em 1923, aconteceu a vinda de novos estudantes, docentes e servidores. Neste mesmo ano despontou uma atitude inconveniente, ou melhor, uma discórdia entre o dirigente e o Dr. Adolpho Cúrio, efeito que em 01 de julho, em Documento Oficial do Ministério da Agricultura redistribui-o o médico dessa Instituição para outra semelhante. Essa mudança causou descontentamento nos servidores e também no povo de Inconfidentes. Por este mesmo documento, foi indicado o médico temporário o Dr. Euclides Solon de Pontes, que teve seu empossamento de imediato, sendo procedente do Rio de Janeiro. Entretanto no dia 30 de setembro de 1923, com o afastamento do Sr. Theóphilo Tavares Paes, assumiu interinamente a Direção o Dr. Euclides Solon Pontes, médico do Patronato (GUIMARÃES, 2010). 
Segundo a mesma autora, em 24 de novembro de 1923 o Sr. Theóphilo recebeu telegrama do Ministro da Agricultura negando-Ihe o pedido de exoneração do cargo que exercia desde 1920. O governo negou-lhe o pedido porque reconhecia no Sr. Theóphilo um funcionário digno, modelar e cumpridor de seus deveres.

Em 2 de dezembro de 1923, entretanto, como consequência deste ato de recusa, aconteceram várias remoções. O Tenente João Cândido Borges, em 9 de dezembro de 1923, foi designado secretário do Patronato Agrícola "Visconde de Mauá", e em um pequeno espaço de tempo, desempenhava o cargo de instrutor militar do Patronato "Wenceslau Braz", de Caxambu (GUIMARÃES, 2010, p. 183).

\subsection{Função Social do Patronato Agrícola}

De acordo com a Secretaria da Agricultura, competia ao Patronato Agrícola: promover a imigração e colonização no estado; patrocinar o cumprimento dos contratos de imigração; promover a organização e fiscalizar o funcionamento de cooperativas entre os operários agrícolas para assistência médica, farmacêutica e ensino primário.

Segundo Boeira (2010) esta instituição compreendia uma dinâmica entre ensino e trabalho para crianças e jovens dentro de um espaço produtivo, desta forma, a vida do patronato estava diretamente vinculada à vida do núcleo colonial. No cumprimento de suas finalidades, os patronatos eram definidos como núcleos de ensino profissional destinados a habilitar seus internos em horticultura, jardinagem, pomicultura, pecuária e cultivo de plantas industriais, dependendo da região que o patronato fora instalado e da necessidade agroeconômica da região. Havia também atividades de criação de diversos animais, como suínos, galinhas, cavalos e bovinos.

A função trabalho e educação regia a principal proposta dos Patronatos Agrícolas, que era de transformar crianças e adolescentes em jovens trabalhadores. O ensino de ofícios ou arte ocupava grande parte do tempo dos alunos, assim através do trabalho, princípios educativos, de socialização e morais eram apresentados à infância deficiente destes 
menores. Assim regia um modelo de assistência e educação voltadas para as crianças pobres do país (OLIVEIRA, 2012).

\section{A TRAJETÓRIA HISTÓRICA DO PATRONATO AGRÍCOLA "VISCONDE DE MAUÁ"}

O Patronato Agrícola "Visconde de Mauá" da cidade de Inconfidentes/MG teve sua importância para o desenvolvimento do município bem como grande contribuição para o desenvolvimento da educação agrícola e tecnológica, passando por vários momentos e desafios, durante décadas do século XX. Mantendo sua tradição e força com a educação agrícola o Patronato acompanhou diversos momentos históricos, cedendo à força da legislação e procurando se adaptar dentro da história.

Permaneceu assim até o ano de 1934, quando passou a ser denominado de Aprendizado Agrícola, regimentado pelo Decreto $n^{\circ} 24.115$ de 12 de abril de 1934 (BRASIL, 1934a) com regimento interno aprovado em 08 de março de 1934 pelo Decreto n²3.979 (BRASIL, 1934b). Estes procuravam preparar trabalhadores aptos para diversos serviços da propriedade rural explorado de acordo com as modernas práticas agronômicas, por meio dos módulos de medicina veterinária, ensino agrícola, zootecnia e indústrias rurais. Os próprios alunos realizavam a limpeza diária da escola e o relacionamento pedagógico e administrativo seguia as mesmas normas do Patronato.

O Aprendizado Agrícola de Minas Gerais permaneceu entre o período de 1934 a 1939 e implementou o curso Primário e o Profissional. As informações de serviços eram mantidas com as divisões do Departamento de Administração com a delegação do Tribunal de Contas, a Delegacia Fiscal do Tesouro Nacional, e sempre em harmonia com a Seção de Administração da Superintendência de Ensino Agrícola e Veterinário (SEAV). Por oportuno, o boletim de avaliação dos discentes era remetido à esta Superintendência nos primeiros dias do mês seguinte e, nele havia o aproveitamento, comportamento e a frequência de cada um, assim como, o resultado da produção agrícola, caso houvesse, incluso frutos e hortaliças, 
ovos e o leite discriminados pelas raças de animais que os produziam, ou seja, tudo que se produzia no campo era relatado junto à SEAV (BRASIL, 1918-1991).

Atendendo ao Decreto-Lei no 1.029 de 06 de janeiro de 1939 (BRASIL, 1939), atribuía-se nova nomenclatura aos Aprendizados Agrícolas de Minas Gerais que passou a denominar-se de Aprendizado Agrícola "Visconde de Mauá", como todos os outros congêneres, verdadeiros centros de irradiação de ensino técnico. Foram criados para ministrar instrução profissional agrícola aos filhos e órfãos de pequenos e médios proprietários rurais, dos trabalhadores da gleba, e dos operários da indústria agrícola.

Além do primário, com duração de quatro anos e do profissional, com duração de dois anos, a escola recebeu determinação de manter simultaneamente os cursos de ensino rural e de adaptação, de acordo com a Portaria n 708, de 27 de dezembro de 1943 (GUIMARÃES, 2010, p. 197). Em seguida, obedecendo ao artigo $2^{\circ}$ do Decreto 14.252 de 10/12/1943 (BRASIL, 1943), a escola dividiu em núcleos de agricultura, zootecnia, indústrias rurais e administração. No mês de maio de 1945, o Aprendizado Agrícola Visconde de Mauá, dotado de caráter rígido, ordenado em sistema de ensino eficaz na disseminação da dicotomia teoria e prática, tanto no campo agrícola como nas artes-ofícios e nas salas de aula, teve que passar por reformas materiais, sem, contudo, abster-se do seu papel educacional, pedagógico e profissional.

Mais tarde, pelo artigo $3^{\circ}$ do Decreto $n^{\circ} 22.506$ de 22 de janeiro de 1947 (BRASIL, 1947), o Aprendizado Agrícola "Visconde de Mauá" passou a denominar-se Escola de Iniciação Agrícola "Visconde de Mauá", de acordo com a Lei Orgânica do Ensino Agrícola implementada pelo Decreto-Lei $n^{\circ}$ 9.613 de 20 de agosto de 1946 (BRASIL, 1946).

Sua função era dar suporte organizacional ao ensino agrícola, com vistas a melhor adequação técnica profissional dos operários da agricultura, estando presentes ideias como a diversificação agrícola, preparação da mão de obra para quem já havia passado da idade escolar e cursos rápidos de capacitação técnica. Nesse sentido, o ensino seria ministrado em dois 
ciclos, onde cada ciclo abarcava os cursos implantados dividido em três modalidades: formação, continuação e aperfeiçoamento. A partir de 1947, ocorreu variação no critério de contratação de pessoal, o quadro se ampliou para 54 funcionários e sete professores. Neste mesmo ano, para atender a Portaria 01 de 16/01/1947, implantam-se as baterias de exame vestibular, através de uma Comissão de Vestibular, em 27 de dezembro de 1946, composta por cinco docentes (BRASIL, 1918-1991). Outro aspecto é que em novembro de 1947 abre-se um centro de treinamento para formação de trabalhadores rurais, com capacidade para 15 alunos, de acordo com ofício n 389 de 23/10/1947, da Comissão Brasileira Americana de Educação das Populações Rurais com vistas a atender os objetivos específicos na preparação do operário agrícola, infelizmente extinto em maio de 1948, para frustração dos espectadores em treinamento (trainee).

O ano de 1950 pode ser visto como um marco na historicização da Escola de Iniciação Agrícola "Visconde de Mauá", já que pelo Decreto n 27.745, de 31 de janeiro de 1950 (BRASIL, 1950), foi elevada a categoria de Escola Agrícola, passando desse modo a intitular-se Escola Agrícola "Visconde de Mauá", vindo a conservar os cursos de Iniciação Agrícola e Mestria Agrícola de sua antecessora. Em 24 de fevereiro deste ano houve, segundo Guimarães (2010, p. 206) a aula inaugural comemorativa da instalação do curso de mestria, oficializando-se, assim, sua elevação à escola agrícola. Como a escola dispunha de novos métodos, recursos, de maneira a implementar e alavancar o ensino técnico-profissionalizante, partindo inclusive, para uma nova fração de tarefas capazes de refletir uma instituição de cunho mais didático-pedagógico na disseminação da dicotomia teoria e prática, logicamente destacou-se com brilho na região.

De acordo com dados levantados dos arquivos do Patronato "Visconde de Mauá", percebe-se que os indicadores educacionais de 1950 a 1963 revelam procedência bastante diversificada de candidatos, vindos de quase todos os estados da República Federativa para estudar na escola agrícola; afinal dado ao progresso alcançado por esta, envolto de culturas e criações com técnicas mais avançadas, despertou o brilho e se destacou no 
cenário de ensino como uma das melhores no País (BRASIL, 1918-1991). Nessa conjuntura, infere-se que no período de 50 a 1954, a escola registrou um aumento gradativo na matrícula inicial e, no período de 1955 a 63, houve oscilação na matrícula. Ademais, a escola em atenção ao seu regimento interno promove a sua primeira formatura, de muitas, aos cursos de iniciação e mestria em data de 28/12/1951 com participação de autoridades, familiares dos alunos e comunidade de Inconfidentes/MG, e em 28/11/59 a Escola Agrícola entregou à nação 23 Mestres e 37 Operários Agrícolas.

Ressalta-se que por força do regimento da Superintendência de Ensino Agrícola e Veterinário, ratificado pelo Decreto n. 52.666 de 11/10/63 (BRASIL, 1963), propunha instruções às Escolas Agrícolas e de Economia Doméstica Rural da rede federal no preparo de seus regimentos internos, contendo a estrutura geral da organização administrativa. Em seus vários capítulos, o regimento tratava da Diretoria, do Conselho de Professores, da Turma de Administração Escolar, do Setor de Agricultura, do Setor de Zootecnia, do Setor de Indústrias Rurais, entre outros, com a menção a funcionar articulados em regime de mútua colaboração.

Mais tarde, pelo artigo $1^{\circ}$ do Decreto $n^{\circ} 53.558$ de 13 de fevereiro de 1964, a referida Escola Agrícola "Visconde de Mauá" passa a denominar-se de Ginásio Agrícola "Visconde de Mauá", destacando-se com brilho por seu modelo diferencial em prol da região e sob a subordinação Superintendência de Ensino Agrícola e Veterinário até o ano de 1967, quando então por força do Decreto n 60.731 de 19/05/1967 (BRASIL, 1967) a Superintendência de Ensino Agrícola e Veterinário foi transpassada para 0 Ministério da Educação e Cultura (MEC), sob nova denominação de Diretoria de Ensino Agrícola que mais tarde, foi substituída pelo Departamento de Ensino Médio.

No período de 1964 até 1967 a aludida instituição ginasial quase entrou em falência, situação crítica, que obviamente provocou a chamada de seu diretor à cidade do Rio de Janeiro, onde foi informado que a Escola seria fechada por falta de recursos da união. Todavia, verifica-se que o diretor não acatou a decisão anunciada, vindo a ser ameaçado de destituição do 
cargo, o que afigura-se medida um tanto abusiva e ilegal; a qual evidentemente não se consumou à época pelo fato de ter sido designado pelo então Presidente da República, Exmo. Sr. Juscelino Kubitschek de Oliveira.

A partir daí, começou um intenso trabalho para que o Ginásio Agrícola pudesse se manter na ativa, diante do cenário estarrecedor de dificuldades à vista, até porque, vale lembrar, era o período do regime militar; de tal modo que remanescia a precariedade das instalações físicas, pouquíssimos recursos e uma grande redução de alunos, que durou mais cinco anos tal luta a ser vencida com bastante agudeza de espírito.

Nessa conjuntura, esse panorama de turbulência no Ginásio Agrícola começa a dar ar de melhoras, a partir da fundação da Coordenação Nacional do Ensino Agrícola (COAGRI) em 1973, não só para os alunos, mas também em prol de todos os fazendeiros da comunidade no entorno da instituição, que eram beneficiados por meio da oferta de cursos extracurriculares, como por exemplo: cafeicultura ou combate a bernes e carrapatos, contando ainda, com patrocínio de empresas como, Bayer, Acar, Pipmo e IBC; as quais, mais à frente, em 1975, juntamente com instituições governamentais houveram por bem implantar no Ginásio vários projetos a título de suporte como: bovinocultura de leite, cafezal velho, de alho, feijão, soja, aveia, de banana, pomar, horta, avicultura, piscicultura, suinocultura, apicultura, industrialização de frutas, variedade de café resiste à ferrugem e terreiro de café e experimentos com cana de açúcar e leite (BRASIL, 1918-1991).

Em 14/02/1969 em função da Portaria Ministerial n 667/68 do Ministério da Educação e Cultura, que trazia em seu bojo o dever de afinação do ano agrícola em harmonia com ano letivo, utilizado até 1972, muito embora sem resultados aceitáveis, verificou-se no Ginásio o fracionamento do ensino em superior, médio, prático, aprendizado agrícola e ensino primário agrícola (BRASIL, 2007). De acordo com Guimarães (2010, p. 215) em 15 de maio de 1971, no salão nobre do Ginásio Agrícola Visconde de Mauá, com a presença de autoridades civis e religiosas, realizaram-se as solenidades de 
formatura dos alunos concluintes do curso de Mestre Agrícola do ano de 1971, em número de 29 formandos.

Por força do Decreto-Lei no 83.935 de 04/09/1979 (BRASIL, 1979), a razão social Ginásio Agrícola "Visconde de Mauá" é substituída por Escola Agrotécnica Federal de Inconfidentes/MG "Visconde de Mauá", dando-se por oficializada a prospectiva transformação sob a mesma sede situada na Praça Tiradentes, n 416, Centro da cidade de Inconfidentes/MG, e por consequência lógica, em 1980, abole-se o primeiro grau; fulgurando-se o ensino agropecuário abrangido por três séries a nível de $2^{\circ}$ grau estritamente.

Importa destacar-se o fato de que a Escola Agrotécnica Federal de Inconfidentes/MG permaneceu, nessa época, submetido ao regime da COAGRI, Secretaria de $1^{\circ}$ e $2^{\circ}$ graus do MEC, conforme Decreto n. 76.436 de 14/10/75 (BRASIL, 1975), em seu artigo $3^{\circ}$ : fomentador do ensino agropecuário no Brasil, até novembro de 1986, quando deu lugar à Secretaria de Ensino de $2^{\circ}$ Grau (SESG), que em 1990 foi renomeada para Secretaria de Ensino Médio e Tecnológico (SENETE) por força do Decreto-Lei n० 99.244 de 10/05/1990 (BRASIL, 1990). Em 1992 a SENETE recebeu o nome de Secretaria de Educação Média e Tecnológica (SEMTEC) mantendo incorporadas a ela, todas as instituições federais de ensino técnico, incluindo a Escola Agrotécnica Federal de Inconfidentes "Visconde de Mauá".

Em 1993, por força da Lei no 8.731 de 16/11/1993 (BRASIL, 1993) a Escola Agrotécnica Federal passou a ser autarquia federal, com autonomia própria e, ainda, didática e disciplinar, cabendo à SEMTEC as atribuições de estabelecer as políticas para a educação tecnológica e exercer a supervisão do ensino técnico federal. Com o status de autarquia, buscou ampliar seu patrimônio com recursos próprios, independente do auxílio da União. De igual modo, conservou a base do sistema Escola-Fazenda e respectivo internato, não outro, perante alteração histórica de seus componentes (clientes) e de seus desígnios de recepção.

Possuía como objetivo, segundo os documentos analisados, preparar o aluno para atuar consciente na sociedade como verdadeiro cidadão, proporcionando-lhes 0 ensino de $2^{\circ}$ grau profissionalizante na sua forma 
regular; nos segmentos de Agropecuária, Enologia, Economia Doméstica e, outras habilitações afins. Ainda, formar o educando para que seja capaz de difundir tecnologias nas áreas de produção, crédito rural, cooperativismo, agroindústria, extensão e outras; servir como polo de desenvolvimento rural dando suporte às atividades de educação comunitária e básica, contribuindo para o aumento da agropecuária local e regional, bem como, cooperar tecnicamente ao ensino agrícola das esferas estadual, municipal e particular. Delimitar o perfil do produto proposto para o final do curso relativo ao ensino médio e, outros fins mais.

Tendo em vista a Lei $n^{\circ} 5.465$ de 03/07/1968 (BRASIL, 1968), conhecida como "Lei do Boi", preconizava em seu bojo o percentual de $50 \%$ das vagas a candidatos agricultores ou filhos destes, proprietários ou não de terras que moravam com suas famílias no meio rural; obviamente, o corpo discente da Escola até 1984 concentrava $75 \%$ oriundos da zona rural. Todavia, esse cenário passou a mudar por força da Lei no 7.423 de 17/12/1985 (BRASIL, 1985) que extinguiu a "Lei do Boi", quando então, a Escola registrou percentual de $63 \%$ de alunos vindos da área urbana e $27 \%$ da área rural, para um total de 413 matrículas efetuadas.

Com a revogação da COAGRI em novembro de 1986, por força do Decreto $n^{\circ} 93.613$ (BRASIL, 1986), a Escola Agrotécnica Federal ficou à deriva, de tal modo que, sentiu os reflexos em seu processo educativo e produtivo de maneira fracionada, mas, contudo, não teve seu desenvolvimento paralisado. Isso porque, a partir de 1986 com vistas a aperfeiçoar seu processo educativo para o ano vindouro (1987), deu início a um planejamento anual composto de duas fases, onde a diretoria, o corpo docente, técnico e administrativo e os líderes de classe, elaboravam suas sugestões, abordando com ênfase os pontos positivos e negativos da Escola.

Desse modo, no primeiro momento, consistia na discussão do calendário, planejamento do exame de seleção, período de adaptação dos novatos de $1^{a}$ série, previsão de eventos, atividades paralelas, critérios de avaliação, confecção de apostilas, rodízio de férias, integração entre disciplinas, análise da situação das unidades educacionais de produção e 
até a fixação dos horários. A segunda fase, direcionava-se à análise do currículo pela supervisão pedagógica com os professores por área de ensino, para ver as metas não alcançadas, devendo com isso, apontar e organizar as proposições de saída para tanto (BRASIL, 1918-1991).

Houve uma evolução das grades curriculares de 1978 a 1990 em decorrência da implementação do curso de Técnico Agrícola (BRASIL, 19181991).

O sistema Escola-Fazenda deu sua consolidação, nas Escolas Agrotécnicas por volta de 1969-1970, após aguçado estudo realizado pela Fundação Centro Nacional de Aperfeiçoamento de Pessoal para a Formação Profissional (CENAFOR), órgão instituído pelo Decreto-Lei n 616 de 09 junho de 1969 (BRASIL, 1969), sendo reestruturado e readaptado pela Coordenação Nacional do Ensino Agrícola (COAGRI) a partir de 1973; ano de fundação desta. Contudo, a metodologia do sistema Escola-Fazenda intensifica-se na década de 1980, com o desígnio de tornar a experiência do trabalho o elemento primordial para a formação do aluno já como parte integrante de todo o processo, imbuído na concepção "aprender a fazer e fazer para aprender", transcendendo-se à comunidade a experiência vivenciada. Saliente-se, que referido sistema, revestia-se de 04 (quatro) segmentos diferentes, com missão de funcionar integrado e interligado; sendo eles: sala de aula, laboratórios de prática e produção, programa agrícola orientado e cooperativa-escola (BRASIL, 1918-1991).

Havia o sistema de monitoria para os alunos da $3^{a}$ série junto às unidades educativas de produção e Cooperativa Escola, com vistas ao desenvolvimento de suas capacidades sócio-afetivas; co-participando ativamente na elaboração e execução dos trabalhos educativos a absorver aprendizagem. Também o plantão aos fins de semana e rodízio de férias, com o intuito de dar seguimento às atividades e projetos da Escola, sendo composto pelos docentes e discentes das três séries. A somar, também o estágio supervisionado, decorrente da Lei nº 6.494 de 07/12/1977 (BRASIL, 1977) regulada pelo Decreto $n^{\circ} 87.497$ de 18 de agosto 1982 (BRASIL, 1982). Desse modo, o estágio como parte do currículo escolar à obtenção da 
habilitação do curso, é a oportunidade que o discente tem de desvencilhar a dicotomia teoria-prática na disseminação de todo conteúdo absorvido pela Escola, visando o seu aperfeiçoamento cognoscível e as relações sociais que se fixam no mercado de trabalho com visão crítica sobre o fim que rodeia o exercício de uma profissão.

Em novembro de 2004 a Escola Agrotécnica Federal de Inconfidentes, finalizou o projeto pedagógico do Curso Superior de Tecnologia em Gestão Ambiental na Agropecuária (Área profissional: Meio Ambiente), o qual foi autorizado, em caráter experimental, pelo MEC, através da Portaria n 4.244 de 21 de dezembro de 2004 (MEC, 2004), nascendo assim, seu primeiro curso superior.

No ano de 2008, a Escola Agrotécnica Federal de Inconfidentes "Visconde de Mauá" passou a ser chamado de Instituto Federal de Educação, Ciência e Tecnologia do Sul de Minas Gerais (IFSULDEMINAS) Campus Inconfidentes, através da Chamada Pública MEC/SETEC n 002/2007 (MEC, 2007), tendo como base o modelo proposto pelo Decreto $n^{\circ}$ 6.095/2007 da Presidência da República (BRASIL, 2007).

Com isso foi promulgada a Lei $n^{0} 11.892$ de 29 de dezembro de 2008, que instituiu a Rede Federal de Educação Profissional, Científica e Tecnológica e que criou os Institutos Federais de Educação (BRASIL, 2008). Assim o IFSULDEMINAS passou a ter forte inserção na área de pesquisa, extensão e inovação, estimulando o desenvolvimento de soluções técnicas e tecnológicas. Sua implantação foi uma ação do Plano de Desenvolvimento da Educação (PDE) do Governo Federal que promoveu o processo democrático do conhecimento à comunidade através das instituições da Rede Federal de Educação Profissional e Tecnológica.

A estrutura multicampi começou a constituir-se em 2008, quando a Lei $N^{\circ} \quad 11.892 / 2008$ transformou as Escolas Agrotécnicas Federais de Inconfidentes, Machado e Muzambinho em Campus Inconfidentes, Campus Machado e Campus Muzambinho do IFSULDEMINAS, cuja Reitoria fica, desde então, em Pouso Alegre. 
Em 2009 estes três Campi iniciais lançaram polos de rede em Passos, Poços de Caldas e Pouso Alegre, os quais se converteram nos Campus Passos, Campus Poços de Caldas e Campus Pouso Alegre. Em 2013, foram criados os Campus avançados de Carmo de Minas e de Três Corações. Os Campi avançados derivaram de polos de rede estabelecidos na região do Circuito das Águas Mineiro, que foi protocolado no Ministério da Educação, em 2011, como região prioritária da expansão.

Compete aos Campi prestar os serviços educacionais para as comunidades em que se inserem. A competência estruturante da Reitoria influencia a prestação educacional concreta no dia a dia dos campi.

A Reitoria comporta cinco pró-reitorias a saber: Pró-Reitoria de Ensino; Pró-Reitoria de Pesquisa, Pós-Graduação e Inovação; Pró-Reitoria de Extensão; Pró-Reitoria de Planejamento e Administração; Pró-Reitoria de Desenvolvimento Institucional.

O IFSULDEMINAS possui a missão de "promover a excelência na oferta da educação profissional e tecnológica, em todos os níveis, formando cidadãos críticos, criativos, competentes e humanistas, articulando ensino, pesquisa e extensão e contribuindo para o desenvolvimento sustentável do Sul de Minas Gerais".

O marco referencial do Projeto Pedagógico Institucional (PDI) do IFSULDEMINAS se deu em agosto de 2009, com a realização de um seminário com todos os servidores do Instituto, bem como da colaboração de especialistas da área de educação brasileira.

Atualmente o Campus Inconfidentes possui uma área total de 254,32 hectares, com $36.000 \mathrm{~m}^{2}$ de área construída.

Segundo Ortigara (2012) no nível hierárquico como a Direção Geral, não teve mudanças nas funções administrativas. Desde sua criação houve aumento do número das funções administrativas no Departamento de Desenvolvimento Educacional (DDE) e no Departamento de Administração e Planejamento (DAP).

O Campus Inconfidentes, atualmente, possui Unidades Educacionais de Produção voltadas à parte zootécnica, agrícola e agroindustrial. Conta 
também com diversos laboratórios, biblioteca equipada com salas de estudos, que oferece acesso à internet e salas de aulas com equipamentos audiovisuais como projetores e computadores. Ainda conta com um ginásio poliesportivo para desenvolvimento de atividades físicas e sala de jogos para entretenimento.

Tem avançado na perspectiva da Educação em Direitos Humanos com a constituição da Coordenação de Ações Inclusivas (CAln), que possui sob sua responsabilidade o Núcleo de Apoio às Pessoas com Necessidades Específicas (NAPNE), visando atender educandos com limitação para o desempenho das atividades acadêmicas; o Núcleo de Estudos e Pesquisas em Gênero, Educação e Sexualidade (NEGES) e o Núcleo de Estudos e Pesquisas Afro-Brasileiros e Indígenas (NEABI).

O Campus Inconfidentes está promovendo a acessibilidade por meio da adequação de sua infraestrutura física e curricular, como a inclusão da disciplina de Libras (Língua Brasileira de Sinais) e a inserção na estrutura curricular de seus cursos de temáticas que abordem as políticas inclusivas, como preveem os Decretos $n^{\circ} 5.626$ de 22 de dezembro de 2005 (BRASIL, 2005) e no 5.296 de 02 de dezembro de 2004 (BRASIL, 2004).

Busca também o crescimento e o desenvolvimento dos seus alunos por meio de atividades artístico-culturais, esportivas e cívicas como seminários, jornadas científicas e tecnológicas, campeonatos esportivos, fanfarra, orquestras, coral, grupo de dança, grupo de teatro, entre outros.

Oferece atualmente, no ensino superior, os Cursos de Tecnologia em Gestão Ambiental, Tecnologia de Redes de Computadores, Engenharia Agronômica, Engenharia de Agrimensura e Cartográfica, Engenharia de Alimentos, Licenciatura em Matemática, Licenciatura em Ciências Biológicas, Licenciatura em Educação do Campo, área Ciência Agrárias, Especialização em Gestão Ambiental, Especialização em Gestão Ambiental para a Polícia Militar e Especialização em Educação Infantil. No ensino técnico integrado, oferece os cursos: Técnico em Agrimensura, Técnico em Agropecuária, Técnico em Alimentos, Técnico em Informática e Técnico em Administração na modalidade PROEJA. 
Desde o ano de 2010, o Campus Inconfidentes vem atuando também na modalidade de Ensino a Distância.

\section{CONSIDERAÇÕES FINAIS}

O Patronato Agrícola "Visconde de Mauá" da cidade de Inconfidentes/MG teve sua importância para o desenvolvimento do município bem como grande contribuição para o desenvolvimento da educação agrícola e tecnológica, passando por vários momentos e desafios, durante décadas do século XX. Mantendo sua tradição e força com a educação agrícola o Patronato acompanhou diversos momentos históricos, cedendo à força da legislação e procurando se adaptar dentro da história.

Analisando historicamente o Patronato Agrícola "Visconde de Mauá", hoje Instituto Federal de Educação Ciência e Tecnologia do Sul de Minas Gerais (IFSULDEMINAS) - Campus Inconfidentes, podemos relatar sua trajetória resumida em: Aprendizado Agrícola de Minas Gerais (1934); Aprendizado Agrícola "Visconde de Mauá (1943); Escola de Iniciação Agrícola "Visconde de Mauá" (1947); Escola Agrícola "Visconde de Mauá" (1950); Ginásio Agrícola "Visconde de Mauá (1964); Escola Agrotécnica Federal de Inconfidentes/MG (1979) e por fim, Instituto Federal de Educação, Ciência e Tecnologia do Sul de Minas Gerais (IFSULDEMINAS) - Campus Inconfidentes (2008).

O estudo desta trajetória nos mostrou o quanto o desenvolvimento do município de Inconfidentes, sul de Minas Gerais, está entrelaçado com a história educacional, ofertada ao longo do tempo que permitiu não só formar os jovens para a sociedade, mas, contribuiu significantemente para que o município se destacasse como um polo importante na área educacional. 


\section{REFERÊNCIAS}

BOEIRA, D. A. Os dez primeiros anos do Núcleo Colonial Anitápolis (19071917). Monografia (Graduação em História). Florianópolis: Universidade Federal de Santa Catarina, 2010.

BRASIL. Presidência da República. Decreto $n^{\circ} \mathbf{1 2 . 8 9 3}$ de 28 de fevereiro de 1918. Autoriza o Ministro da Agricultura a crear patronatos agrícolas, para educação de menores desvalidos, nos postos zootéchnicos, fazendasmodelo de criação núcleos coloniaes, e outros estabelecimentos do Ministério. Diário Oficial da União, Seção 1, 05/03/1918, Página 2963 (Publicação Original). Brasília, DF. Disponível em: < http://www2.camara.leg.br/legin/fed/decret/1910-1919/decreto-12893-28fevereiro-1918-507076-publicacaooriginal-1-pe.html>. Acesso em 05 de novembro de 2017.

BRASIL. Presidência da República. Decreto n 13.706, de 25 de julho de 1919. Resolve aprovar o regulamento dos patronatos agrícolas. Diário Oficial da União, Seção 1, 27/07/1919, Página 10623 (Republicação). Brasília, DF. Disponível em: < http://www2.camara.leg.br/legin/fed/decret/19101919/decreto-13706-25-julho-1919-521010-republicacao-95833-pe.html>. Acesso em 05 de novembro de 2017.

BRASIL. Presidência da República. Decreto n²4.115, de 12 de Abril de 1934a. Resolve sôbre a organização definitiva dos estabelecimentos de ensino elementar de agricultura, subordinados à Diretoria do Ensino Agrícola, do Departamento Nacional, da Produção Vegetal, e dá outra providências. Diário Oficial da União, Seção 1, 19/04/1934, Página 7583 (Publicação Original). Brasília, DF. Disponível em:

<http://www2.camara.leg.br/legin/fed/decret/1930-1939/decreto-241 15-12abril-1934-512582-publicacaooriginal-1-pe.html >. Acesso em 05 de novembro de 2017.

BRASIL. Presidência da República. Decreto $n^{\circ}$ 23.979, de 8 de Março de 1934b. Extingue no Ministério da Agricultura a Diretoria Geral de Pesquisas Cientificas, criada, pelo decreto ${ }^{\circ} 22.338$, de 11 de janeiro de 1933, aprova os regulamento das diversas dependencias do mesmo Ministério, consolida a legislação referente à reorganização por que acaba de passar e dá outras providências. Diário Oficial da União, Seção 1, 04/04/1934, Página 6345 (Publicação Original). Brasília, DF. Disponível em: <http://www2.camara.leg.br/legin/fed/decret/1930-1939/decreto-23979-8marco-1934-499088-publicacaooriginal-1-pe.html>. Acesso em 05 de novembro de 2017.

BRASIL. Retrospectiva Histórica da Escola Agrotécnica Federal de Inconfidentes. Inconfidentes: EAFI, 1918-1991. 
BRASIL. Presidência da República. Decreto-Lei n 1029, de 06 de janeiro de 1939. Dá denominações aos Aprendizados Agrícolas do Ministério da Agricultura. Rio de Janeiro, RJ. Disponível em:

<http://legis.senado.leg.br/legislacao/PublicacaoSigen.action? id=524680\&tip oDocumento=DEL\&tipoTexto=PUB >. Acesso em 05 de novembro de 2017.

BRASIL. Presidência da República. Decreto $n^{\circ}$ 14.252, 10 de dezembro de 1943. Aprova o Regimento dos Aprendizados Agrícolas. Rio de Janeiro, RJ.

BRASIL. Presidência da República. Decreto n 22.506, 22 de Janeiro de 1947. Altera a denominação de estabelecimento de ensino Agrícola, subordinados ao Ministério da Agricultura. Diário Oficial da União, Seção 1 , 25/01/1947, Página 1148 (Publicação Original). Disponível em: <http://www2.camara.leg.br/legin/fed/decret/1940-1949/decreto-22506-22janeiro-1947-34 1 153-publicacaooriginal-1-pe.html>. Acesso em 05 de novembro de 2017.

BRASIL. Presidência da República. Decreto n 9.613 de 20 de agosto de 1946. Lei Orgânica do Ensino Agrícola. Diário Oficial da União, Seção 1, 23/08/1946, Página 12019 (Publicação Original). Disponível em:

<http://www2.camara.leg.br/legin/fed/declei/1940-1949/decreto-lei-9613-20agosto-1946-453681-publicacaooriginal-1-pe.html>. Acesso em 05 de novembro de 2017.

BRASIL. Presidência da República. Decreto n²7.745, de 31 de janeiro de 1950. Transforma em Escola Agrícola a Escola de Iniciação Agrícola Visconde de Mauá. Diário Oficial da União, Seção 1, 02/02/1950, Página 1580 (Publicação Original). Disponível em: <http://www2.camara.leg.br/legin/fed/decret/1950-1959/decreto-27745-31janeiro-1950-324517-publicacaooriginal-1-pe.html>. Acesso em 05 de novembro de 2017.

BRASIL. Presidência da República. Decreto n 52.666, 11 de outubro de 1963. Aprova o Regimento da Superintendência do Ensino Agrícola e Veterinário, do Ministério da Agricultura. Diário Oficial da União, Seção 1, 25/10/1963, Página 9009 (Publicação Original). Disponível em:

<http://www2.camara.leg.br/legin/fed/decret/1960-1969/decreto-52666-11outubro-1963-392917-publicacaooriginal-1-pe.html>. Acesso em 05 de novembro de 2017.

BRASIL. Presidência da República. Decreto $n^{\circ} 53.558$ de 13 de fevereiro de 1964. Altera denominação de escolas de iniciação agrícola, agrícolas e agrotécnicas. Diário Oficial da União, Seção 1, 14/02/1964, Página 1433 (Publicação Original). Disponível em: <http://www2.camara.leg.br/legin/fed/decret/1960-1969/decreto-53558-13fevereiro-1964-393545-publicacaooriginal-1-pe.html>. Acesso em 05 de novembro de 2017. 
BRASIL. Presidência da República. Decreto n 60.731, de 19 de Maio de 1967. Transfere para o Ministério da Educação e Cultura os órgãos de ensino do Ministério da Agricultura e dá outras providências. Diário Oficial da União, Seção 1, 22/05/1967, Página 5543 (Publicação Original). Disponível em: <http://www2.camara.leg.br/legin/fed/decret/1960-1969/decreto-60731-19maio-1967-401466-publicacaooriginal-1-pe.html>. Acesso em 05 de novembro de 2017.

BRASIL. Presidência da República. Decreto n $^{\circ}$ 83.935, de 4 de setembro de 1979. Altera a denominação dos estabelecimentos de ensino que indica. Diário Oficial da União, Seção 1, 05/09/1979, Página 12890 (Publicação Original). Disponível em: <http://www2.camara.leg.br/legin/fed/decret/19701979/decreto-83935-4-setembro-1979-433451-publicacaooriginal-1-pe.html>. Acesso em 05 de novembro de 2017.

BRASIL. Presidência da República. Decreto $n^{\circ}$ 76.436, de 14 de Outubro de 1975. Altera o Decreto $n^{\circ} 72.434$, de 9 de julho de 1973, que criou a Coordenação Nacional do Ensino Agrícola do Ministério da Educação e Cultura. Diário Oficial da União, Seção 1, 15/10/1975, Página 13665 (Publicação Original). Disponível em: <http://www2.camara.leg.br/legin/fed/decret/1970-1979/decreto-76436-14outubro-1975-425010-publicacaooriginal-1-pe.html>. Acesso em 05 de novembro de 2017.

BRASIL. Presidência da República. Decreto n 99.244, de 10 de maio de 1990. Dispõe sobre a reorganização e o funcionamento dos órgãos da Presidência da República e dos Ministérios, e dá outras providências. Disponível em: <http://www.planalto.gov.br/ccivil_03/decreto/D99244.htm>. Acesso em 05 de novembro de 2017.

BRASIL. Presidência da República. Lei n 8731 de 16 de novembro 1993. Transforma as Escolas Agrotécnicas Federais em Autarquias e da Outras providências. Diário Oficial da União, Seção 1, 17/11/1993, Página 17253 (Publicação Original). Brasília, DF. Disponível em: <http://www2.camara.leg.br/legin/fed/lei/1993/lei-8731-16-novembro-1993349599-publicacaooriginal-1-pl.html>. Acesso em 05 de novembro de 2017.

BRASIL. Presidência da República. Lei n 5.465 de 3 de Julho de 1968. Dispõe sôbre o preenchimento de vagas nos estabelecimentos de ensino agrícola. Diário Oficial da União, Seção 1, 04/07/1968, Página 5537 (Publicação Original). Disponível em: <http://www2.camara.leg.br/legin/fed/lei/19601969/lei-5465-3-julho-1968-358564-publicacaooriginal-1-pl.html>. Acesso em 05 de novembro de 2017.

BRASIL. Presidência da República. Lei n 7.423 de 17 de dezembro de 1985. Revoga a Lei $n^{\circ}$ 5.465, de 3 de julho de 1968, que "dispõe sobre o preenchimento de vagas nos estabelecimentos de ensino agrícola", bem 
como sua legislação complementar. Disponível em:

<http://www.planalto.gov.br/ccivil_03/leis/1980-1988/L7423.htm>. Acesso em 05 de novembro de 2017.

BRASIL. Presidência da República. Decreto n 93.613 de 21 de novembro de 1986. Extingue órgãos do Ministério da Educação, e dá outras providências. Disponível em: <http://www.planalto.gov.br/ccivil_03/decreto/19801989/1985-1987/D93613impressao.htm>. Acesso em 05 de novembro de 2017.

BRASIL. Presidência da República. Decreto Lei n 616, de 9 de junho de 1969. Autoriza o Poder Executivo a instituir o Centro Nacional de Aperfeiçoamento de Pessoal para a Formação Profissional - CENAFOR e dá outras providências. Disponível em: <http://www.planalto.gov.br/ccivil_03/decretolei/1965-1988/Del0616.htm>. Acesso em 05 de novembro de 2017.

BRASIL. Presidência da República. Lei n 6.494 de 7 de dezembro de 1977. Dispõe sobre os estágios de estudantes de estabelecimento de ensino superior e ensino profissionalizante do $2^{\circ}$ Grau e Supletivo e dá outras providências. Disponível em:

<http://www.planalto.gov.br/ccivil_03/leis/L6494impressao.htm>. Acesso em 05 de novembro de 2017.

BRASIL. Presidência da República. Decreto n 87.497 de 18 de agosto de 1982. Regulamenta a Lei $n^{\circ}$ 6.494, de 07 de dezembro de 1977, que dispõe sobre o estágio de estudantes de estabelecimentos de ensino superior e de $2^{\circ}$ grau regular e supletivo, nos limites que especifica e dá outras providências. Disponível em: <http://www.planalto.gov.br/ccivil_03/decreto/d87497.htm>. Acesso em 05 de novembro de 2017.

BRASIL. Presidência da República. Decreto $n^{\circ}$. 6.095, 24 de abril de 2007. Estabelece diretrizes para o processo de integração de Instituições Federais de Educação Tecnológica, para fins de constituição dos Institutos Federais de Educação, Ciência e Tecnologia - IFET, no âmbito da Rede Federal de Educação Tecnológica. Disponível em:

$<$ http://www.planalto.gov.br/ccivil_03/_ato2007-

2010/2007/decreto/d6095.htm>. Acesso em 05 de novembro de 2017.

BRASIL. Presidência da República. Lei n 11.892 de 29 de dezembro de 2008. Institui a Rede Federal de Educação Profissional, Científica e Tecnológica, cria os Institutos Federais de Educação, Ciência e Tecnologia, e dá outras providências. Diário Oficial da União 30/12/2008. Disponível em: <http://www.planalto.gov.br/ccivil_03/_ato2007-2010/2008/lei/l1 1892.htm>. Acesso em 05 de novembro de 2017.

BRASIL. Presidência da República. Decreto $\mathrm{n}^{\circ} 5.626$ de 22 de dezembro de 2005. Regulamenta a Lei $n^{\circ} 10.436$, de 24 de abril de 2002, que dispõe sobre a Língua Brasileira de Sinais - Libras, e o art. 18 da Lei n¹0.098, de 19 de 
dezembro de 2000. Disponível em:

<http://www.planalto.gov.br/ccivil_03/_ato2004-

2006/2005/decreto/d5626.htm>. Acesso em 05 de novembro de 2017.

BRASIL. Presidência da República. Decreto $n^{\circ} 5.296$ de 2 de dezembro de 2004. Regulamenta as Leis nos 10.048 , de 8 de novembro de 2000, que dá prioridade de atendimento às pessoas que especifica, e 10.098, de 19 de dezembro de 2000, que estabelece normas gerais e critérios básicos para a promoção da acessibilidade das pessoas portadoras de deficiência ou com mobilidade reduzida, e dá outras providências. Disponível em:

<http://www.planalto.gov.br/ccivil_03/_ato2004-

2006/2004/decreto/d5296.htm>. Acesso em 05 de novembro de 2017.

GUIMARÃES, L. M. Inconfidentes a terra que me viu nascer: aspectos

históricos gerais. Ouro Fino - MG: O Autor, 2010.544p

MEC - Ministério da Educação. Chamada Pública MEC/SETEC n. 002/2007. Disponível em:

<http://portal.mec.gov.br/arquivos/pdf/chamada_publica_ifet.pdf>. Acesso em 05 de novembro de 2017.

MEC - Ministério da Educação. Portaria n. 4.244 de 21 de dezembro de 2004. Disponível em:

<http://sites.unasp.edu.br/portal/secretariageral/Documentos/BDE/2004-

2/658-22-12-04.pdf>. Acesso em 05 de novembro de 2017.

NERY, M. A. A. M. Aprendizados e patronatos: um cortejo entre dois modelos de ensino agrícola das primeiras décadas do século XX (1911-1934). Revista Tempos e Espaços em Educação, v.2, p.25-32 jan./jun. 2009.

ORTIGARA, C. Reformas educacionais no período Lula (2003-2010). Tese (doutorado). Universidade Estadual de Campinas, Faculdade de Educação. Campinas, SP. 2012.

OLIVEIRA, M. R. P. Educar e Regenerar: Os Patronatos Agrícolas e a infância pobre na Primeira República. Viçosa: Universidade Federal de Viçosa, 2012.

SILVA, M. L. da. Reminiscências - Capítulos da História do Patronato Agrícola. João Pessoa, PB: Ed. Oficinas Gráficas da União, 1994.

Recebido em: Fevereiro de 2018 Aprovado em: Junho de 2018 